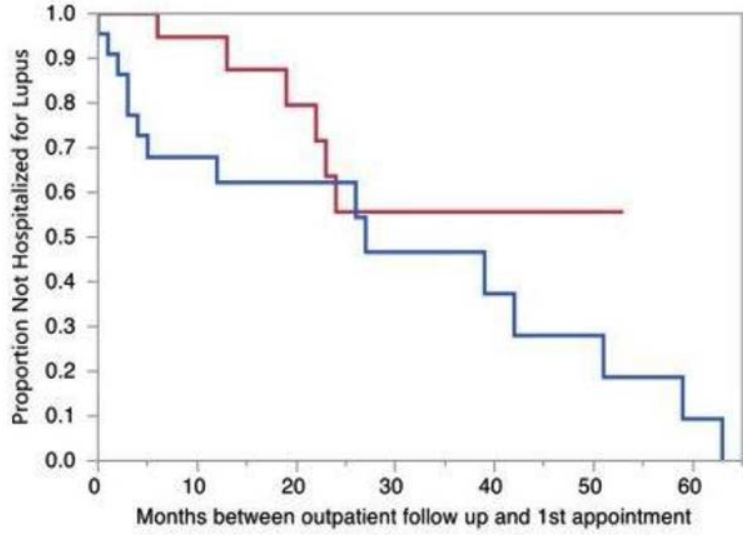

- Score $<19$

Score $>=19$

Figure 1. Kaplan- Meier Survival Analysis comparing the risk of hospitalization between the groups with 2019 Lupus classification criteria score (CCS) of less than 19 (red) and more/equal to 19 (blue). A time-dependent effect, with the admission free survival curves crossing at two years (Figure 1), indicated a 1 out of 3 chance of lupus related admission during the first 6 months for a high CCS score $>=19$.

Conclusion: We failed to validate the EHR algorithm identifying patients at high risk for lupus hospitalization in our less severely affected cohort with fewer admission events to analyze. Nonetheless, "criteria counting" using the weightings of the 2019 lupus classification criteria was granular enough to make these case finding criteria themselves prognostic for future hospitalization risk. It is likely that existing EHRs, using protocols based upon classification criteria scores, are now capable of predicting survival, costs, and admissions automatically. References:

[1] D Li et al. Determining risk factors that increase hospitalizations in patients with systemic lupus erythematosus, Lupus (2018) 27, 1321-1328

[2] Carneiro et al. A comparison of three classification criteria sets for Systemic Lupus Erythematosus - a study looking at links to outcome and mortality; Arthritis Care Res (Hoboken). 2019 Sep 10. doi: 10.1002/acr.24061

Disclosure of Interests: Saurav Suman: None declared, Mervat Eissa: None declared, Heidi Rogers: None declared, Aleksander Lenert: None declared, Arnold Stromberg: None declared, william roberts Shareholder of: Own Stocks of Pfizer and Novartis

DOI: 10.1136/annrheumdis-2020-eular.1752

\section{AB1232 ORAL DYSBIOSIS REFLECTS THE IMMUNOLOGICAL ALTERATION OF RA REGARDING TO ACPA AND HLA DRB1*SE: NAGASAKI ISLAND STUDY}

Y. Tsuiji ${ }^{1}$, M. Tamai ${ }^{1}$, S. Morimoto ${ }^{1}$, D. Sasaki ${ }^{1}$, M. Nagayoshi ${ }^{2}$, F. Nonaka ${ }^{1}$, S. Y. Kawashiri ${ }^{1}$, K. Yanagihara ${ }^{1}$, T. Saito ${ }^{1}$, K. Aoyagi ${ }^{1}$, T. Maeda ${ }^{3}$, F. Matsuda ${ }^{4}$, A. Kawakami ${ }^{1}{ }^{1}$ Nagasaki University, Nagasaki, Japan; ${ }^{2}$ National Institute of Public Health, Wako, Japan; ${ }^{3}$ Nagasaki University, Department of General Medicine, Nagasaki, Japan; ${ }^{4}$ Kyoto University, Kyoto, Japan

Background: Anti-citrullinated protein antibody (ACPA) production is observed in several organs even prior to the onset of rheumatoid arthritis (RA), and oral mucosa is considered to be one of the important tissues. The presence of HLADRB1*SE closely associates with ACPA production. Saliva is considered to reflect the oral microbiota including periodontal disease. Alteration of oral microbiota of RA becomes to be normalized by DMARDs treatment, however, the interaction of HLA-DRB $1{ }^{*}$ SE, ACPA and oral microbiota of RA patients remains to be elucidated. Objectives: The Nagasaki Island Study, which had started in 2014 collaborating with Goto City, is intended for research of the preclinical stage of RA, including ACPA/HLA genotype screening and ultrasound and magnetic resonance imaging examinations in high-risk subjects. Using the samples accumulated in this cohort, we have tried to investigate the difference of oral microbiota among RA patients and healthy subjects regarding to ACPA and HLA-DRB1 ${ }^{*} \mathrm{SE}$.

Methods: Blood and salivary samples were obtained from 1422 subjects out of 4276 who have participated in the Nagasaki Island Study from 2016 to 2018. ACPA positivity was $1.7 \%$ in total. Some of RA patients resided in Goto City participated in the Nagasaki Island Study. At this point, we selected 291 subjects, who were ACPA positive non-RA healthy subjects $(n=22)$ and patients with RA ( $n=33,11$ subjects were ACPA positive and 22 ACPA negative respectively) as the case, age and gender matched ACPA negative non-RA healthy subjects $(n=236)$ as the control. ACPA was measured by an enzyme-linked immunosorbent assay, and HLA genotyping was quantified by next-generation sequencing (Ref.1). The operational taxonomic unit (OUT) analysis using 16S rRNA gene sequencing were performed. The richness of microbial diversity within-subject (alpha diversity) was scaled via Shannon entropy. The dissimilarity between microbial community composition was calculated using Bray-Curtis distance as a scale, and differences between groups (beta diversity) were tested by permutational multivariate analysis of variance (PERMANOVA). In addition, UniFrac distance calculated in consideration of the distance on the phylogenetic tree were performed. Results: Median age 70 y.o., \% Female $58.8 \%$. Among RA and non-RA subjects, not alpha diversity but beta diversity was statistically significance $(p=0.022$ small in RA). In RA subjects, both alpha and beta diversity is small $(p<0.0001)$, especially significant in ACPA positive RA (Figure 1). Amongt RA subjects, presence of HLA-DRB1 ${ }^{*}$ SE did not show the difference but the tendency of being small of alpha diversity $(p=0.29)$.

Conclusion: Our study has suggested for the first time the association of oral microbiota alteration with the presence of ACPA and HLA-DRB1*SE. Oral dysbiosis may reflect the immunological status of patients with RA.

References:

[1] Kawaguchi S, et al. Methods Mol Biol 2018;1802: 22

Disclosure of Interests: None declared

DOI: 10.1136/annrheumdis-2020-eular.5147

\begin{tabular}{|l|l}
\hline AB1233 & GENDER DIFFERENCE IN DISEASE SEVERITY \\
AND TREATMENT OUTCOMES AMONG PATIENTS \\
WITH RHEUMATOID ARTHRITIS (RA), AXIAL \\
SPONDYLOARTHRITIS (AXSPA) AND PSORIATIC \\
ARTHRITIS (PSA) STARTING TREATMENT WITH \\
TARGETED THERAPY IN THE CZECH REPUBLIC
\end{tabular}

J. Zavada ${ }^{1}$, L. Nekvindova ${ }^{2}$, K. Pavelka ${ }^{1}$, P. Horak ${ }^{3}$, J. Vencovský ${ }^{1}$ on behalf of collaborators of the ATTRA registry. ${ }^{1}$ Institute of Rheumatology, Prague, Czech Republic; ${ }^{2}$ Institute of Biostatistics and Analyses, Faculty of Medicine, Masaryk University, Brno, Czech Republic; ${ }^{3}$ Faculty of Medicine and Dentistry, Palacký University, 3rd Department of Internal Medicine-Nephrology, Rheumatology, Endocrinology, Olomouc, Czech Republic

Background: The ATTRA registry captures more than $95 \%$ of patients with $\mathrm{RA}, \mathrm{AxSpA}$, or PSA treated with biologics in the Czech Republic (CZ). In CZ, anti-TNF therapy is reimbursed for RA if DAS28 $>5.1$ despite therapy with csDMARDs, for PSA if disease is not "adequately controlled" with csDMARDs and for AS if BASDAI $>4$ and CRP/ESR elevated above normal.

Objectives: We aimed to investigate gender-related differences in baseline characteristics and treatment effectiveness among patients with RA, AxSpa, and PsA starting first targeted therapy (TT) in CZ.

Methods: In this observational cohort study, the ATTRA register provided prospectively collected data on RA, AxSpA and PsA patients who initiated their first TT (mostly by TNFi) in 2012-6/2018. Treatment effectiveness and adherence was assessed at 12 months by a change in patient-reported outcomes (PROs), CRP and \% drug survival. Differences in categorical and continuous data btw males and females were assessed using the Pearson $\mathrm{X}^{2}$ test (of Fisher exact test, as appropriate), or Mann-Whitney test resp. This study was largely descriptive, and no statistical adjustments have been made.

Results: A total of 1602 RA, 1306 AxSpa, and 493 PsA patients were included. The difference in baseline characteristics btw women and men starting TT are shown in table 1. Their response and adherence to TT after one year is shown in table 2.

Conclusion: When starting their first TT, males tended to have higher levels of CRP, while females were more often (ex)smokers and reported worse parameters of quality of life across the diagnostic groups. The improvement of PROs was similar in males and females, while males with axSpA and PsA showed large improvements in CRP. Survival on drug at one year was similar, save for AxSpA, where males showed better survival.

\begin{tabular}{|c|c|c|c|c|c|c|c|c|c|}
\hline & & $(n=1602)$ & & & $A(n=1306)$ & & & $A(n=493)$ & \\
\hline & M & $\frac{f(n-1002)}{F}$ & p & M & $\frac{A(n-100)}{F}$ & $p$ & M & $\frac{\pi(n-490)}{F}$ & $p$ \\
\hline$N(\%)$ & $359(22.485)$ & $1243(77.65)$ & & $931(71.3 \mathrm{~S})$ & $375(28.7 \mathrm{~S})$ & & $262(53.18)$ & 231 (46.95) & \\
\hline $\begin{array}{l}\text { Age (yrs) at } \\
\text { start of first } \\
\text { symptoms }\end{array}$ & $\begin{array}{c}47.4 \\
(37.1 ; 54.5)\end{array}$ & $\begin{array}{c}42.8 \\
(33.3 ; 51.4)\end{array}$ & $<0.001$ & $\begin{array}{c}25.5 \\
(19.6 ; 33.0)\end{array}$ & $\begin{array}{c}28.6 \\
(21.6 ; 36.6)\end{array}$ & $<0.00$ & $\begin{array}{c}36.7 \\
(27.7 ; 46.5)\end{array}$ & $\begin{array}{c}38.8 \\
(30.8 ; 47.5)\end{array}$ & 0.083 \\
\hline $\begin{array}{l}\text { Age (yrs) at } \\
\text { diagnosis }\end{array}$ & $\begin{array}{c}48.0 \\
(37.0 ; 55.0)\end{array}$ & $\begin{array}{c}44.0 \\
(34.0 ; 53.0)\end{array}$ & $<0.001$ & $\begin{array}{c}31.0 \\
(24.0 ; 39.0)\end{array}$ & $\begin{array}{c}35.0 \\
(27.0 ; 42.0)\end{array}$ & $<0.00$ & $\begin{array}{c}37.0 \\
(30.0 ; 47.0)\end{array}$ & $\begin{array}{c}38.0 \\
(32.0 ; 49.0)\end{array}$ & 0.171 \\
\hline $\begin{array}{l}\text { Age (yrs } \\
\text { start of }\end{array}$ & $\begin{array}{c}55.0 \\
(46.0 ; 63.0)\end{array}$ & $\begin{array}{c}53.0 \\
(43.0 ; 62.0)\end{array}$ & 076 & & & $\begin{array}{c}<0.00 \\
1\end{array}$ & $\begin{array}{c}48.0 \\
(37.0 ; 55.0)\end{array}$ & $\begin{array}{c}49.0 \\
(40.0 ; 58.0)\end{array}$ & 0.070 \\
\hline $\begin{array}{l}\text { Smoker or ex- } \\
\text { smoker }\end{array}$ & 189 (58. 36$)$ & 729 (655.95) & $<0.001$ & $447(53.68)$ & $197(57.48)$ & $<0.00$ & $100(43.35)$ & $132(63.28)$ & 0.168 \\
\hline $\operatorname{CRP}(\mathrm{mg} / \mathrm{l})$ & $\begin{array}{c}16.5 \\
(90 ; 320\end{array}$ & $\begin{array}{r}14.4 \\
60 ; 2.2\end{array}$ & $<0.001$ & 20. & 0 & $<0.00$ & $\begin{array}{c}16.3 \\
(80 ; 31.8)\end{array}$ & $\begin{array}{c}15.0 \\
(6.123 .7)\end{array}$ & 0.023 \\
\hline $\begin{array}{l}\text { VAS pain } \\
(0-100)\end{array}$ & $\begin{array}{c}70.0 \\
(50.0 ; 80.0)\end{array}$ & $\begin{array}{c}70.0 \\
(55.0 ; 80.0)\end{array}$ & 0.007 & $\begin{array}{c}70.0 \\
(50.0,80.0)\end{array}$ & $\begin{array}{c}70.0 \\
(55.0 ; 80.0)\end{array}$ & 0.292 & $\begin{array}{c}65.0 \\
(45.0 ; 80.0)\end{array}$ & $\begin{array}{c}70.0 \\
(60.0 ; 80.0)\end{array}$ & 001 \\
\hline $\begin{array}{l}\text { VAS fatigue } \\
(0-100)\end{array}$ & $\begin{array}{c}550,0.0 .0) \\
(50.0 ; 80.0)\end{array}$ & $\begin{array}{c}50.0,0.07 \\
70.0 \\
(55.0 ; 85.0)\end{array}$ & $<0.001$ & $\begin{array}{c}(50.0,0.00) \\
(50.0 ; 80.0)\end{array}$ & $\begin{array}{c}(550,0.0) \\
70.0 \\
(55.0 ; 85.0)\end{array}$ & $\begin{array}{c}<0.00 \\
1\end{array}$ & $\begin{array}{c}50.00 \\
(45.0 ; 80.0)\end{array}$ & $\begin{array}{l}75.00 \\
75.0 ; 85.0) \\
(55.0 ;\end{array}$ & $<0.001$ \\
\hline HAQ & $1.4(1.0 ; 1.8)$ & $16(1.3 ; 20)$ & $<<0.001$ & $11(0.8 ; 1.5)$ & $1.3(0.8 ; 1.6)$ & $<0.00$ & $13(0.9 ; 1.5)$ & $1.5(1.0 ; 1.9)$ & \begin{tabular}{|l|c|} 
\\
\end{tabular} \\
\hline$E Q-5 D(0-1)$ & $0.2(0.1 ; 0.7)$ & $0.1(0.0 ; 0.6)$ & $<0.001$ & $0.2(0.1 ; 0.7)$ & $0.2(0.1 ; 0.6)$ & \begin{tabular}{|l|} 
\\
0.035 \\
\end{tabular} & $0.2(0.1 ; 0.7)$ & $0.1(0.1 ; 0.6)$ & \begin{tabular}{|l|}
0.005 \\
\end{tabular} \\
\hline
\end{tabular}




\begin{tabular}{|c|c|c|c|c|c|c|c|c|c|}
\hline & \multicolumn{3}{|c|}{$R A(n=1602)$} & \multicolumn{3}{|c|}{ AxSpA $(n=1306)$} & \multicolumn{3}{|c|}{ PsA $(n=493)$} \\
\hline & M & $\mathrm{F}$ & p & M & $\mathbf{F}$ & $p$ & M & $\mathrm{F}$ & $p$ \\
\hline $\begin{array}{l}\Delta \text { VAS pain } \\
(0-100)\end{array}$ & $\begin{array}{c}-30.0 \\
(-55.0 ;-15.0)\end{array}$ & $\begin{array}{c}-35.0 \\
(-55.0 ;-15.0)\end{array}$ & 0.566 & $\begin{array}{l}-40.0 \\
(-60.0 ;-25.0)\end{array}$ & $\begin{array}{c}-40.0 \\
(-60.0 ;-15.0)\end{array}$ & 0.109 & $\begin{array}{c}-40.0 \\
(-55.0 ;-15.0)\end{array}$ & $\begin{array}{c}-40.0 \\
(-65.0 ;-15.0)\end{array}$ & 0.364 \\
\hline $\begin{array}{l}\Delta \text { VAs fatigue } \\
(0-100)\end{array}$ & $\begin{array}{c}-30.0 \\
(-50.0 ;-10.0)\end{array}$ & $\begin{array}{c}-30.0 \\
(-55.0 ;-10.0)\end{array}$ & 0.734 & $\begin{array}{c}-35.0 \\
(-50.0 ;-15.0)\end{array}$ & $\begin{array}{c}-35.0 \\
(-55.0 ;-10.0)\end{array}$ & 0.738 & $\begin{array}{c}-30.0 \\
(-55.0 ;-15.0)\end{array}$ & $\begin{array}{c}40.0 \\
(-60.0 ;-15.0)\end{array}$ & 0.174 \\
\hline$\triangle H A Q$ & $\begin{array}{c}-0.5 \\
(-0.9 ;-0.1)\end{array}$ & $\begin{array}{c}-0.5 \\
(-1.0 ;-0.1)\end{array}$ & 0.463 & $\begin{array}{c}-0.5 \\
(-0.9 ;-0.1)\end{array}$ & $\begin{array}{c}-0.5 \\
(-0.9 ;-0.1)\end{array}$ & 0.929 & $\begin{array}{c}-0.5 \\
(-0.9 ;-0.3)\end{array}$ & $\begin{array}{c}-0.5 \\
(-0.9 ; 0.0)\end{array}$ & 0.232 \\
\hline$\Delta E Q-5 D(0-1)$ & $0.4(0.0 ; 0.6)$ & $0.5(0.0 ; 0.7)$ & 0.156 & $0.5(0.1 ; 0.6)$ & $0.5(0.1 ; 0.6)$ & 0.602 & $0.5(0.1 ; 0.7)$ & $0.5(0.1 ; 0.7)$ & 0.648 \\
\hline$\triangle C R P$ & $\begin{array}{c}-110 \\
(-25.9 ;-1.0)\end{array}$ & $\begin{array}{c}-7.9 \\
(-20.7 ;-1.0)\end{array}$ & 0.091 & $\begin{array}{c}-149 \\
(-26.6 ;-7.2)\end{array}$ & $\begin{array}{c}-10.0 \\
(-19.5 ;-2.7)\end{array}$ & $<0.001$ & $\begin{array}{c}-11.0 \\
(-27.0 ;-3.1)\end{array}$ & $\begin{array}{c}-8.2 \\
(-20.0 ;-1.7)\end{array}$ & 0.003 \\
\hline Survival (\%) & $\begin{array}{l}80 \\
(76 ; 84)\end{array}$ & $\begin{array}{c}76 \\
(73 ; 78)\end{array}$ & 0.182 & $\begin{array}{c}89 \\
(87 ; 91)\end{array}$ & $\begin{array}{c}79 \\
(75 ; 83)\end{array}$ & $<0.001$ & $\begin{array}{c}88 \\
(84 ; 92)\end{array}$ & $\begin{array}{c}83 \\
(78 ; 88)\end{array}$ & 0.146 \\
\hline
\end{tabular}

Acknowledgments: Supported by project 00023728 of Ministry of Health, CZ Disclosure of Interests: Jakub Zavada Speakers bureau: Abbvie, UCB, Sanofi, Elli-Lilly, Novartis, Zentiva, Accord, Lucie Nekvindova: None declared, Karel Pavelka Consultant of: Abbvie, MSD, BMS, Egis, Roche, UCB, Medac, Pfizer, Biogen, Speakers bureau: Abbvie, MSD, BMS, Egis, Roche, UCB, Medac, Pfizer, Biogen, Pavel Horak Speakers bureau: Pfizer, Abbvie, Eli lilly. Novartis, Roche, Sanofi, Jiří Vencovský: None declared

DOI: 10.1136/annrheumdis-2020-eular.2849

\section{Validation of outcome measures and biomarkers}

\begin{tabular}{|l|l}
\hline AB1234 & MICRO-RNA 155 AND MIR-34A: POSSIBLE \\
& BIOMARKERS OF INFLAMMATORY BURDEN \\
& AND DISEASE ACTIVITY IN ANCA-ASSOCIATED \\
& VASCULITIS WITH RENAL INVOLVEMENT
\end{tabular}

D. Bruno ${ }^{1}$, P. G. Cerasuolo ${ }^{1}$, C. Di Mario ${ }^{1}$, S. L. Bosello ${ }^{1,2}$, L. Gigante ${ }^{1}$, A. Musto ${ }^{1}$, G. Vischini ${ }^{3}$, S. Costanzi ${ }^{3}$, S. Alivernini ${ }^{1}, 2$, B. Tolusso ${ }^{2}$, G. Grandaliano ${ }^{3,4}$, E. Gremese ${ }^{1,2} .{ }^{1}$ Division of Rheumatology, Università Cattolica del Sacro Cuore, Rome, Italy; ${ }^{2}$ Division of Rheumatology, Fondazione Policlinico Universitario A. Gemelli-IRCCS, Rome, Italy; ${ }^{3}$ Division of Nephrology, Fondazione Policlinico Universitario A. Gemelli-IRCCS, Rome, Italy; ${ }^{4}$ Division of Nephrology, Università Cattolica del Sacro Cuore, Rome, Italy

Background: Predicting clinical outcomes in ANCA-related glomerulonephritis remains a major challenge. To date, there is no reliable biomarker able to predict renal prognosis in patients with ANCA-associated vasculitis (AAV). Micro-RNA (miRNA) are non-coding RNAs involved in the fine tuning of immune cells biology and this epigenetic modulation associates with different phenotypes and prognosis in several diseases.

Objectives: To investigate the expression of miR-155 and miR-34a in kidney biopsies of AAV patients according with renal outcome.

Methods: Fifteen patients with AAV and renal involvement (mean age $63.0 \pm 13.3$ years, disease duration $4.9 \pm 2.2$ months), who underwent renal biopsy. Demographic, clinical and autoimmune parameters were recorded for each patient. Each kidney biopsy was classified according to the Berden Classification, Risk group (according to the ANCA Renal Risk Score) and the chronicity Classification of the Mayo Clinic's proposed score.

MiR-155 and miR-34a expression was investigated on kidney biopsy tissue using the miRNeasy FFPE kit (Qiagen). The quantitative expression of miR-155, miR34a and housekeeping gene U1, used as control, was assessed by Real TimePCR. MiR-155 and miR-34a expression was correlated with histopathological and clinical-laboratory parameters.

Each patient was followed for 12 months and renal outcome was considered according to KDIGO CKD Classification. Markers of inflammation (ESR, CRP) and urine analysis data were recorded at baseline and after 12 months.

Results: Six (40\%) patients were p-ANCA positive and $9(60 \%)$ c-ANCA positive. Eight patients (53\%) also had pulmonary involvement. The mean baseline GFR was $30.7 \pm 28.8 \mathrm{ml} / \mathrm{min} / 1.73 \mathrm{~m}^{2}$ and 10 patients $(66 \%)$ showed an active urinary sediment.

At disease onset, the mean expression of miR-155 was $9.5 \pm 21.1$, while the expression of mir-34a was $13.1 \pm 46.2$. Considering the autoimmune profile, kidney tissue of p-ANCA positive patients was enriched of mir-155 (19.6 \pm 30.6 fold) compared to $c$-ANCA positive patients $(1.9 \pm 2.9$ fold; $p=0.001)$. Particularly, considering the renal function, kidney tissue of patients with greater impairment of renal function (KDIGO stage 5) was enriched of miR-155 (21.5 \pm 38.3 fold) compared to patients with less renal impairment (KDIGO stage 1-4) $(4.72 \pm 8.16$ fold, $\mathrm{p}=0.004)$.

Tissue expression of miR-155 and miR-34a did not correlated with the abovementioned histopathological classifications.

After 12 months from kidney biopsy, $3(20 \%)$ patients had a worsening of renal function, $5(33 \%)$ still presented elevated markers of inflammation and $3(20 \%)$ still had proteinuria at urine analysis. At baseline, kidney tissue of patients with higher CRP plasma levels and proteinuria at follow-up presented higher

expression of miR-155 ( $p=0.002$ and $p=0.001)$, whereas no significant differences were found about miR-34a kidney tissue expression.

Conclusion: MiRNAs may play a potential role in the pathogenesis of ANCA-related glomerulonephritis. MiR-155 kidney enrichment seems to mirror the disease inflammatory burden and activity at the onset and after 12 months representing a possible biomarker in ANCA vasculitis with renal involvement. This finding may represent the basis for further studies on miRNA expression in blood samples, aiming to identify a non-invasive biomarker of kidney damage, predicting disease's relapses and patients' prognosis.

References:

[1] Renauer et al, Clin Rev Allergy Immunol. 2016

Disclosure of Interests: Dario Bruno: None declared, Pier Giacomo Cerasuolo: None declared, Clara Di Mario: None declared, Silvia Laura Bosello Speakers bureau: Abbvie, Pfizer, Boehringer, Laura Gigante: None declared, Alessia Musto: None declared, Gisella Vischini: None declared, Stefano Costanzi: None declared, Stefano Alivernini: None declared, Barbara Tolusso: None declared, Giuseppe Grandaliano: None declared, Elisa Gremese Speakers bureau: Abbvie, BMS, Celgene, Jannsen, Lilly, MSD, Novartis, Pfizer, Sandoz, UCB DOI: 10.1136/annrheumdis-2020-eular.6011

\section{$\mathrm{AB} 1235$} AS A BIOMARKER FOR SJÖGREN SYNDROME - A PROSPECTIVE OBSERVATIONAL STUDY

P. Chebbi ${ }^{1}$, J. Kabeer ${ }^{1}$, P. Sandhya ${ }^{1}$, M. Gowri ${ }^{1}$, D. Danda ${ }^{1} .{ }^{1}$ CMC Vellore, Tamil Nadu, India

\section{Background:}

Objectives: Calprotectin (MRP 8/14) is secreted by neutrophils and monocytes in an inflammatory milieu(1). Increased levels of calprotectin in blood and faeces has been previously shown in patients with primary Sjogren's syndrome(pSS)(2) We hypothesised Calprotectin in saliva may therefore potentially reflect inflammation in salivary glands. In the present study, we aimed to assess the utility of salivary calprotectin as a biomarker in pSS and to evaluate the potential association of calprotectin with clinical features, laboratory markers and disease activity indexes in pSS.

Methods: Consecutive patients attending rheumatology clinic between September 2016 and July 2017 of age more than 18 years fulfilling either American European Consensus Group (AECG) 2002 or 2016 American College of Rheumatology/European League Against Rheumatism Classification Criteria for Primary Sjogren's Syndrome, constituted the case group. Patients with sicca non-pSS and rheumatoid arthritis patients satisfying ACR/EULAR criteria 2010 were recruited as disease controls. Age and sex-matched healthy subjects were recruited as a controls. Patient history, signs and symptoms, laboratory investigations, ESSDAI and ESSPRI scoring were noted for cases and disease controls. Unstimulated saliva was collected by the spitting method. Salivary calprotectin levels were quantified by commercially available ELISA kit(R\&D Systems, MN, USA).

Results: A total of 42 pSS cases (41.5911.21 years, 40 women), 40 disease controls (47.629.81 years, 39 women) and 30 healthy controls (3610.65 years, 29 women) were recruited. In pSS and disease controls, the median levels of salivary calprotectin $[38.5(81)$ and $52(69.5 \mathrm{ng} / \mathrm{ml})]$ were significantly higher compared to healthy controls $[26.5(29)\{p=0.001\}]$. Salivary calprotectin levels in $p S S$ was positively associated with oral symptoms and negatively associated with immunosuppression of 1 year and more $(\mathrm{P}=0.04$ and 0.03 respectively $)$, but not ESSDAI,ESSPRI scores or lab parameters.

Conclusion: Salivary calprotectin was elevated in pSS compared to healthy subjects and was found to be positively associated with oral symptoms and with immunosuppressive treatment.

References: [1]Stroncek DF, Shankar RA, Skubitz KM. The subcellular distribution of myeloid-related protein 8 (MRP8) and MRP14 in human neutrophils. J Transl Med. 2005 Sep 28;3:36.

[2] Fagerhol MK, Larsen A, Brun JG, Hammer HB, Angel K, Kvien TK, et al. Large molecular size EDTA-resistant complexes containing S100A12, ERAC, in serum during inflammatory conditions. Scand J Clin Lab Invest. 2012 Apr;72(2):129-36.

Disclosure of Interests: None declared

DOI: 10.1136/annrheumdis-2020-eular.6216

\section{$\mathrm{AB} 1236$ KL-6 AS A BIOMARKER FOR SJÖGREN SYNDROME- ASSOCIATED INTERSTITIAL LUNG DISEASE: METHODOLOGY MATTERS}

Y. H. Chiu', C. C. Lu', F. C. Liu', S. E. Tang ${ }^{2}$, S. J. Chu' ${ }^{1}$, S. Y. Kuo ${ }^{1}$, H. C. Chen ${ }^{1}$ ${ }^{1}$ Tri-Service General Hospital, National Defense Medical Center, Division of Rheumatology/Immunology/Allergy, Taipei, Taiwan, Republic of China; ${ }^{2}$ Tri-Service General Hospital, National Defense Medical Center, Division of Thoracic Medicine and Critical Care, Taipei, Taiwan, Republic of China 